\title{
Fluorescence Turn-on Visualization of Microscopic Processes for Self-healing Gels by AIEgens and Anti-counterfeiting Application
}

Jiangman Sun, ${ }^{\dagger}$ Jianguo Wang, ${ }^{\ddagger}$ Ming Chen, ${ }^{\ddagger}$ Xiong Pu, $"$ Guan Wang, ${ }^{\dagger}$ Lin $\mathrm{Li},{ }^{\dagger}$ Guanyu Chen, ${ }^{\dagger}$ Yuanjing Cai, ${ }^{\dagger}$ Xinggui $\mathrm{Gu},{ }^{*}, \dagger$ and Ben Zhong Tang ${ }^{*, \ddagger, \S}$

${ }^{\dagger}$ Beijing Advanced Innovation Center for Soft Matter Science and Engineering, College of Materials Science and Engineering, State Key Laboratory of Chemical Resource Engineering, Beijing University of Chemical Technology, Beijing 100029, China.

‡Department of Chemistry, Hong Kong Branch of Chinese National Engineering Research Center for Tissue Restoration and Reconstruction, and Institute for Advanced Study, The Hong Kong University of Science and Technology, Clear Water Bay, Kowloon, Hong Kong, China.

§Center for Aggregation-Induced Emission, SCUT-HKUST Joint Research Institute, State Key Laboratory of Luminescent Materials and Devices, South China University of Technology, Guangzhou 510640,

China.

"CAS Center for Excellence in Nanoscience, Beijing Key Laboratory of Micro-nano Energy and Sensor, Beijing Institute of Nanoenergy and Nanosystems, Chinese Academy of Sciences, Beijing 100083, China. 


\section{Experimental Section}

\section{Materials.}

All of the reagents and solvents used were purchased from J\&K and Sigma-Aldrich, and used without further purification. Bis(amine)-terminated poly-(dimethylsiloxane) $\left(\mathrm{M}_{\mathrm{n}}: 5000-7000\right.$ g mol $^{-1}$, DMS-A21) was purchased from Gelest. ${ }^{1} \mathrm{H}$ NMR and ${ }^{13} \mathrm{C}$ NMR spectra were measured on a Bruker ARX $400 \mathrm{MHz}$ spectrometer. High-resolution mass spectrometry (HRMS) were recorded on a GCT Premier CAB 048 mass spectrometer operating in MALDITOF mode.

\section{Preparation of fluorescent self-healing PDMS gels.}

Healable AIEgen-containing PDMS gel was synthesized by mixing $0.8 \mathrm{~g}$ of bis(amine)terminated poly-(dimethylsiloxane) and $0.4 \mathrm{~mL}$ solution of $0.26 \mathrm{M} \mathrm{1,3,5-triformylbenzene}$ and $2.5 \times 10^{-5} \mathrm{M}$ fluorophores (TPE-4CHO, TPP-4CHO or BT-TPE-4CHO) in dimethylformamide (DMF). The mixture was dried in a polyvinylidene fluorid (PVDF) container $(20 \mathrm{~mm} \times 30 \mathrm{~mm} \times 5 \mathrm{~mm})$ at room temperature for 2 days and heated at $70{ }^{\circ} \mathrm{C}$ for 5h. Imine bonds were formed, and the PDMS chains were cross-linked to generate the transparent and fluorescent self-healing gels.

Characterization of the steady-state spectra. The steady-state absorption and transmittance test were carried out by a Shimadzu UV-2600 UV-vis spectrophotometer. Photoluminescence (PL) spectra was measured on a FLSP9200 fluorescence spectrophotometer (Edinburgh Instruments Ltd, UK).

\section{Measurements of the gel-forming and self-healing dynamics.}

A FLSP9200 fluorescence spectrophotometer (Edinburgh Instruments Ltd, UK) was used for characterizing the gel-forming dynamic. The precursors ( $0.8 \mathrm{~g}$ of bis(amine)-terminated poly-

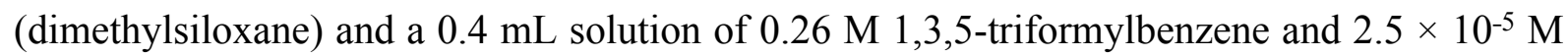
TPE-4CHO) were mixed in the container and measured the photoluminescence (PL) spectra every 10 minutes at room temperature. Confocal laser micro-Raman spectrometer 
(HORIBA/LabRAM HR Evolution) was used for measuring the self-healing dynamic. The TPE-4CHO-containing PDMS film and blank film were cut by a commercial razor blade respectively and put them together, followed by focusing the laser point on the boundary of blank film where was next to the TPE-4CHO-containing PDMS film and then measured the PL spectra every 30 minutes at room temperature during the healing process.

\section{Fluorescence images.}

The fluorescent images of self-healing process were obtained by confocal lasing scanning microscopy (Leica/TCS SP8), Laser line UV 405nm, Green Channel (498-568nm). The TPE4CHO-containing PDMS film was cut by a commercial razor blade then take the fluorescent photos every 30 minutes at room temperature during the healing process.

\section{Mechanical tensile test.}

The mechanical tensile tests were measured by an ESM301/Mark-10 system. The gauge dimensions of tested samples are about $10 \mathrm{~mm} \times 5 \mathrm{~mm} \times 0.4 \mathrm{~mm}$. For the tensile test, the train rate was fixed at $30 \mathrm{~mm} / \mathrm{min}$. For mechanical healing tests, the samples were cut completely by a commercial razor blade, followed by healing at ambient conditions for $6 \mathrm{~h}$.

\section{Code scan.}

The fluorescent code was scanned by a commercially available free application software named "COLORCODETM" downloaded from Apple app store by a smartphone.

\section{Synthesis of TPE-4CHO.}

TPE-4CHO was synthesized according to the previous report. ${ }^{1}$

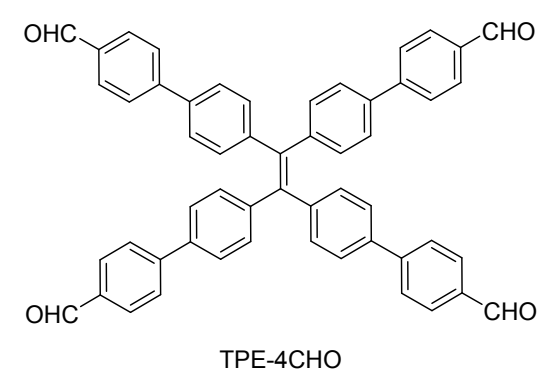

Scheme S1. The chemical structure of TPE-4CHO. 


\section{Synthesis and characterization of TPP-4CHO and BT-TPE-4CHO.}
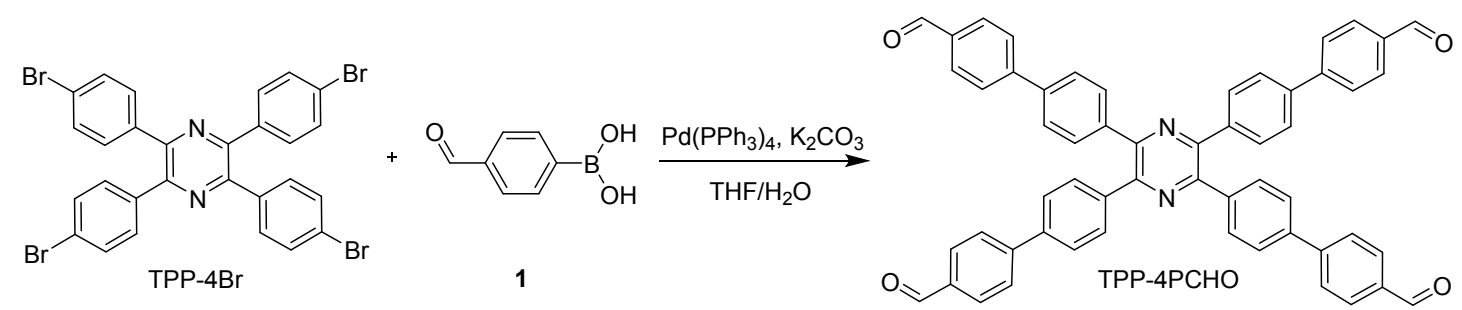

Scheme S2. Synthetic route to TPP-4CHO.

\section{Synthesis of TPP-4CHO.}

TPP-4Br was synthesized according to the literature. ${ }^{2}$ Into a $250 \mathrm{~mL}$ round bottom flask was added $2 \mathrm{~g}(2.9 \mathrm{mmol})$ of TPP-4Br, $1.9 \mathrm{~g}(12.7 \mathrm{mmol})$ of $\mathbf{1}, 0.66 \mathrm{~g}(0.6 \mathrm{mmol})$ of $\mathrm{Pd}\left(\mathrm{PPh}_{3}\right)_{4}$, $60 \mathrm{~mL}$ of THF, and $8.28 \mathrm{~g}$ of $\mathrm{K}_{2} \mathrm{CO}_{3}$ (dissolved in $30 \mathrm{~mL}$ of water) under nitrogen. The mixture was stirred at $80{ }^{\circ} \mathrm{C}$ overnight. After that, the mixture was cooled down to the room temperature and condensed under reduced pressure to remove the solvent. The residual was dissolved with a large amount of DCM and washed by water several times. The collected organic phase was condensed under reduced pressure, the residual powder was refluxed in $\mathrm{MeOH}$ several times and the final product was collected by filtration. A pale white powder of $0.7 \mathrm{~g}(0.87 \mathrm{mmol})$ was obtained in a yield of $30 \% .{ }^{1} \mathrm{HNMR}\left(400 \mathrm{MHz}, \mathrm{CDCl}_{3}\right), \delta(\mathrm{ppm})$ : $10.10(\mathrm{~s}, 4 \mathrm{H}), 8.01$ (d, $J=8.0 \mathrm{~Hz}, 8 \mathrm{H}), 7.90(\mathrm{~d}, J=8 \mathrm{~Hz}, 8 \mathrm{H}), 7.85(\mathrm{~d}, J=8 \mathrm{~Hz}, 8 \mathrm{H}), 7.1$ (d, $J=8 \mathrm{~Hz}, 8 \mathrm{H}$ ). HRMS (MALDI-TOF): $m / z\left[\mathrm{M}^{+}\right]$calculated for $\mathrm{C}_{56} \mathrm{H}_{36} \mathrm{~N}_{2} \mathrm{O}_{4}: 800.2675$, found: 800.2696 . 

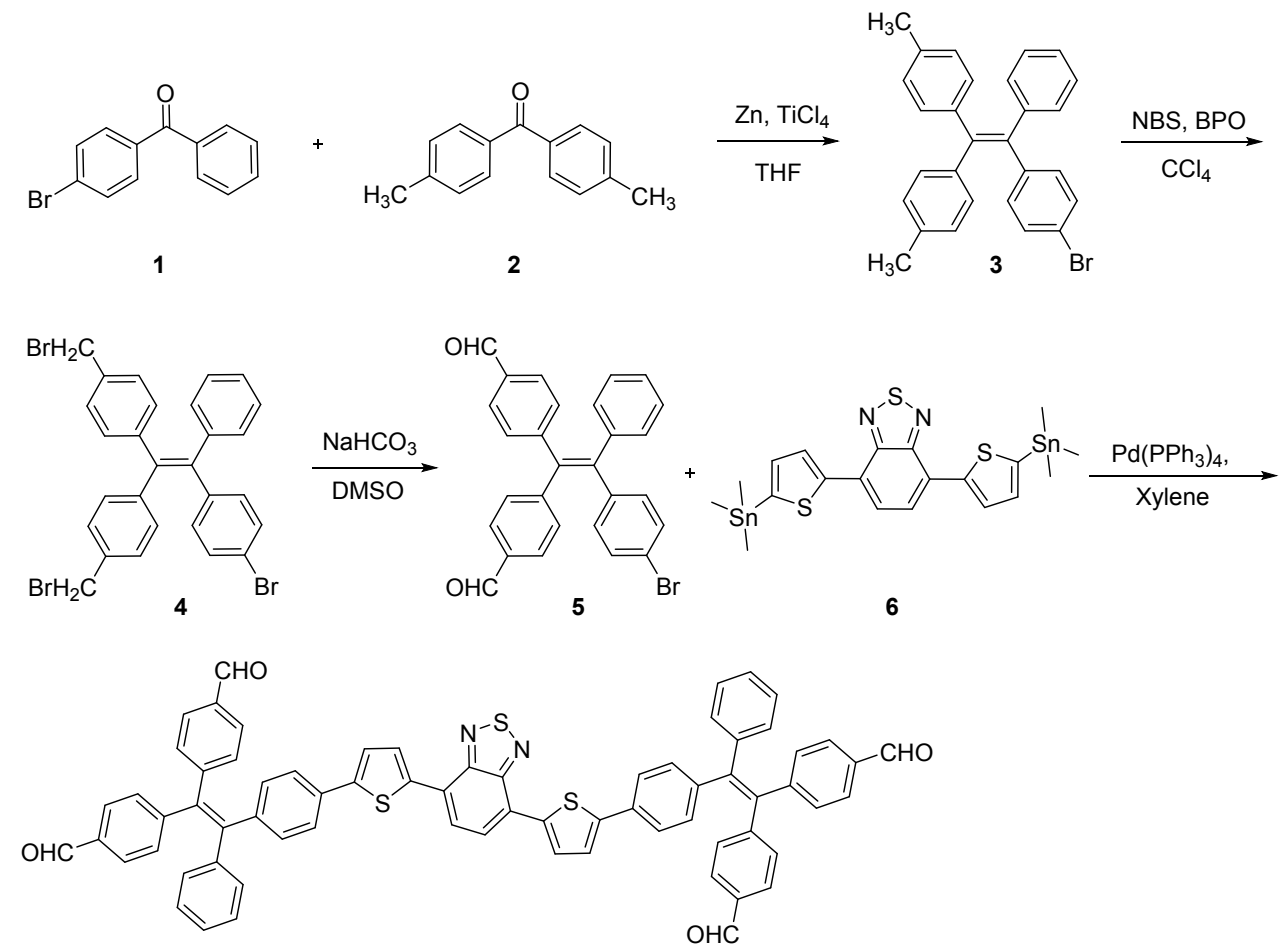

BT-TPE-4CHO

Scheme S3. Synthetic route to TPP-4PCHO.

\section{4,4'-(2-(4-bromophenyl)-2-phenylethene-1,1-diyl)bis(methylbenzene) (3). $3.1 \mathrm{~g}$ of $\mathrm{Zn}$}

powder was added into a pre-dried two necked round-bottom flask with a magnetic stirrer and a reflux condenser. The flask was degassed and flushed with nitrogen three times. $150 \mathrm{~mL}$ of anhydrous THF was injected into the flask and the mixture was cooled to $-78{ }^{\circ} \mathrm{C}$, then 2.67 $\mathrm{mL}$ of titanium tetrachloride $\left(\mathrm{TiCl}_{4}\right)$ was injected into the flask drop by drop. After that, the mixture was allowed to warm up to room temperature and stirred for another 30 minutes at room temperature, then refluxed at $80{ }^{\circ} \mathrm{C}$ for $2 \mathrm{~h}$. Then a mixture of $2.61 \mathrm{~g}$ (4bromophenyl)(phenyl)methanone (1) and $2.1 \mathrm{~g}$ di-p-tolylmethanone (2) in $20 \mathrm{~mL}$ THF was injected to the reaction system and refluxed for another $3 \mathrm{~h}$. The reaction was quenched with a $10 \% \mathrm{~K}_{2} \mathrm{CO}_{3}$ aqueous solution and filtered. The filtration was then extracted with $\mathrm{CH}_{2} \mathrm{Cl}_{2}$, washed with $\mathrm{NaCl}$ (aq.) and the aqueous layer was extracted with $\mathrm{CH}_{2} \mathrm{Cl}_{2}$ twice. The combined organic fractions were dried over anhydrous $\mathrm{Na}_{2} \mathrm{SO}_{4}$. After filtration and solvent evaporation, the crude product was purified by silica gel column chromatography to give $\mathbf{3}$ $(1.3 \mathrm{~g})$ as light yellow solid in $30 \%$ yield. ${ }^{1} \mathrm{H}$ NMR (400 MHz, $\left.\mathrm{CD}_{2} \mathrm{Cl}_{2}\right), \delta(\mathrm{ppm}): 7.28(\mathrm{~d}, J=$ 
$4.0 \mathrm{~Hz}, 1 \mathrm{H}), 7.26(\mathrm{~d}, J=4.0 \mathrm{~Hz}, 1 \mathrm{H}), 7.16-7.14(\mathrm{~m}, J=8.0 \mathrm{~Hz}, 3 \mathrm{H}), 7.06-7.04(\mathrm{~m}, 2 \mathrm{H}), 6.99$ $(\mathrm{d}, J=8.0 \mathrm{~Hz}, 2 \mathrm{H}), 6.97-6.91(\mathrm{~m}, 8 \mathrm{H}), 2.31(\mathrm{~s}, 3 \mathrm{H}), 2.28(\mathrm{~s}, 3 \mathrm{H}) .{ }^{13} \mathrm{C} \mathrm{NMR}(100 \mathrm{MHz}$ $\left.\mathrm{CD}_{2} \mathrm{Cl}_{2}\right) \delta(\mathrm{ppm}): 144.03,143.62,142.01,141.09,140.98,139.14,136.88,136.73,133.34$ $131.56,131.49,131.39,131.36131 .12,128.87,128.69,128.11,126.77,120.39,21.25,21.22$. HRMS (MALDI-TOF):m/z [M+] calculated for $\mathrm{C}_{28} \mathrm{H}_{21} \mathrm{Br}_{3}$ : 438.09776, found: 438.09767.

4,4'-(2-(4-bromophenyl)-2-phenylethene-1,1-diyl)dibenzaldehyde (5). 2 mmol compound 3 (0.8 g), $4.5 \mathrm{mmol}$ N-bromosuccinimide (NBS, $0.8 \mathrm{~g}$ ) and benzoyl peroxide (BPO, $12 \mathrm{mg}$ ) were added to a round-bottom flask with a reflux condenser, followed by degassing and flushing with nitrogen three times. $30 \mathrm{ml} \mathrm{CHCl}_{3}$ was injected to the round-bottom flask. After refluxed for $12 \mathrm{~h}$, the mixture was cooled to room temperature and filtered to remove succinimide. The filtrate was evaporated under reduced pressure. Then the crude product (4) and $\mathrm{NaHCO}_{3}(0.37 \mathrm{~g})$ were added into a round-bottom flask with a reflux condenser, followed by degassing and flushing with nitrogen three times. Then $12 \mathrm{~mL}$ DMSO was added to the mixture and stirred at $95{ }^{\circ} \mathrm{C}$ for $4 \mathrm{~h}$. The mixture was cooled back to r.t., diluted with water, and extracted twice with EtOAc. The organic layer was dried over anhydrous $\mathrm{Na}_{2} \mathrm{SO}_{4}$. After filtration and solvent evaporation, the crude product was purified by silica gel column chromatography and $5(187 \mathrm{mg})$ was obtained as a light yellow solid with a yield of $20 \%$. ${ }^{1} \mathrm{H}$ NMR (400 MHz, DMSO), $\delta$ (ppm): 9.93 (s, 1H), 9.91 (s, 1H), 7.75 (d, J=8.0 Hz, 2H), 7.71 $(\mathrm{d}, J=8.0 \mathrm{~Hz}, 2 \mathrm{H}), 7.40(\mathrm{~d}, J=8 \mathrm{~Hz}, 2 \mathrm{H}), 7.25-7.19(\mathrm{~m}, 7 \mathrm{H}), 7.03(\mathrm{t}, J=12.0 \mathrm{~Hz}, 2 \mathrm{H}), 6.97$ (d, $J=8.0 \mathrm{~Hz}, 2 \mathrm{H}) .{ }^{13} \mathrm{C}$ NMR (100 MHz, DMSO) $\delta$ (ppm): 191.93, 149.51, 149.38, 143.88, $142.42,141.95,139.72,135.33,135.23,133.24,132.26,132.20,132.18,131.54,131.53$, 129.72, 129.53, 128.46, 127.95, 121.80. HRMS (MALDI-TOF): $m / z\left[\mathrm{M}^{+}\right]$calculated for $\mathrm{C}_{28} \mathrm{H}_{19} \mathrm{BrO}_{2}$ : 466.05629, found: 466.05631 .

Synthesis of BT-TPE-4CHO. Carefully purified compound 5 (150 mg, $0.32 \mathrm{mmol})$, 4,7bis(5-(trimethylstannyl)thiophen-2-yl)benzo[c][1,2,5]thiadiazole $6(100 \mathrm{mg}, 0.16 \mathrm{mmol})$ and $\mathrm{Pd}\left(\mathrm{PPh}_{3}\right)_{4}(57.8 \mathrm{mg}, 0.05 \mathrm{mmol})$ were added into a round-bottom flask with a reflux 
condenser, followed by degassing and flushing with nitrogen three times. $50 \mathrm{ml}$ xylene was injected to the round-bottom flask. The solution was refluxed with vigorous stirring at $120{ }^{\circ} \mathrm{C}$ for $24 \mathrm{~h}$. The mixture was cooled back to r.t., evaporated the xylene and resolute the residue with $\mathrm{CH}_{2} \mathrm{Cl}_{2}$, washed with $\mathrm{NaCl}$ (aq.) and the aqueous layer was extracted with $\mathrm{CH}_{2} \mathrm{Cl}_{2}$ twice. The combined organic fractions were dried over anhydrous $\mathrm{Na}_{2} \mathrm{SO}_{4}$. After filtration and solvent evaporation, the crude product was purified by silica gel column chromatography to give the object BT-TPE-4CHO (35 mg) as dark red solid in $20 \%$ yield. ${ }^{1} \mathrm{H}$ NMR (400 MHz, $\mathrm{CD}_{2} \mathrm{Cl}_{2}$ ), $\delta$ (ppm): 9.97 (s, 2H), 9.95 (s, 2H), 8.15 (d, $\left.J=4.0 \mathrm{~Hz}, 2 \mathrm{H}\right), 7.95$ (s, 2H), 7.73 (d, $J$ $=8.0 \mathrm{~Hz}, 4 \mathrm{H}), 7.68(\mathrm{~d}, J=8.0 \mathrm{~Hz}, 4 \mathrm{H}), 7.54(\mathrm{~d}, J=8.0 \mathrm{~Hz}, 4 \mathrm{H}), 7.45(\mathrm{~d}, J=4.0 \mathrm{~Hz}, 2 \mathrm{H})$, $7.31(\mathrm{~d}, J=8.0 \mathrm{~Hz}, 4 \mathrm{H}), 7.25(\mathrm{~d}, J=8.0 \mathrm{~Hz}, 4 \mathrm{H}), 7.23-7.19(\mathrm{~m}, 6 \mathrm{H}), 7.14-7.11(\mathrm{~m}, 8 \mathrm{H}) .{ }^{13} \mathrm{C}$ NMR (100 MHz, $\left.\mathrm{CD}_{2} \mathrm{Cl}_{2}\right) \delta(\mathrm{ppm}): 191.98,152.90,149.81,149.77,145.26,144.61,142.76$, $142.54,139.45,139.26,135.29,135.16,133.38,132.31,131.67,129.72,129.53,129.07$, 128.44, 127.90, 126.00, 125.71, 125.45, 124.72. HRMS (MALDI-TOF): $\mathrm{m} / z\left[\mathrm{M}^{+}\right]$calculated for $\mathrm{C}_{70} \mathrm{H}_{44} \mathrm{~N}_{2} \mathrm{O}_{4} \mathrm{~S}_{3}: 1072.24577$, found: 1072.24607.

\section{Characterizations of TPE-4CHO, TPP-4CHO, BT-TPE-4CHO}




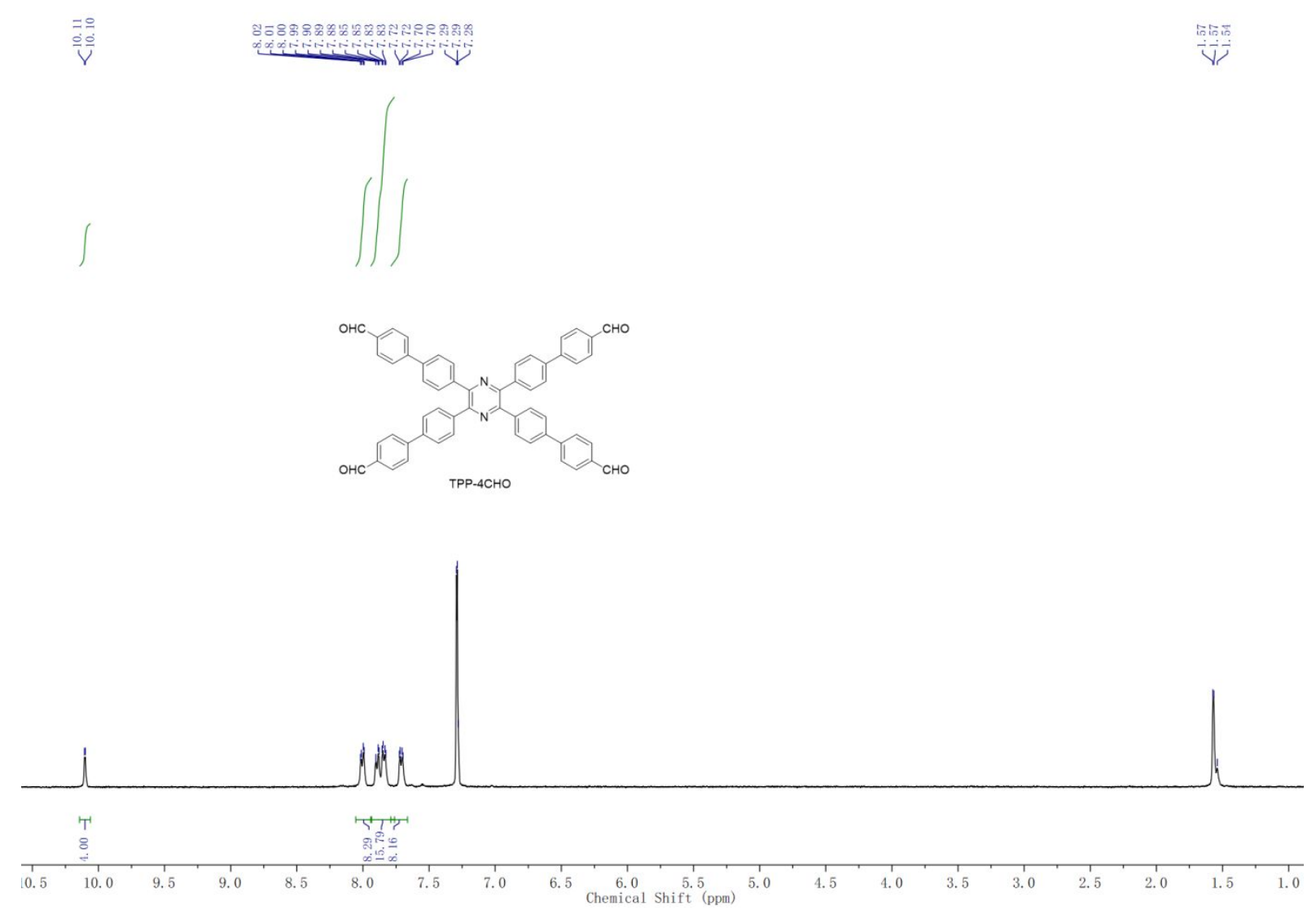

Figure S1. ${ }^{1} \mathrm{H}$ NMR spectrum of TPP-4CHO in $\mathrm{CDCl}_{3}$.

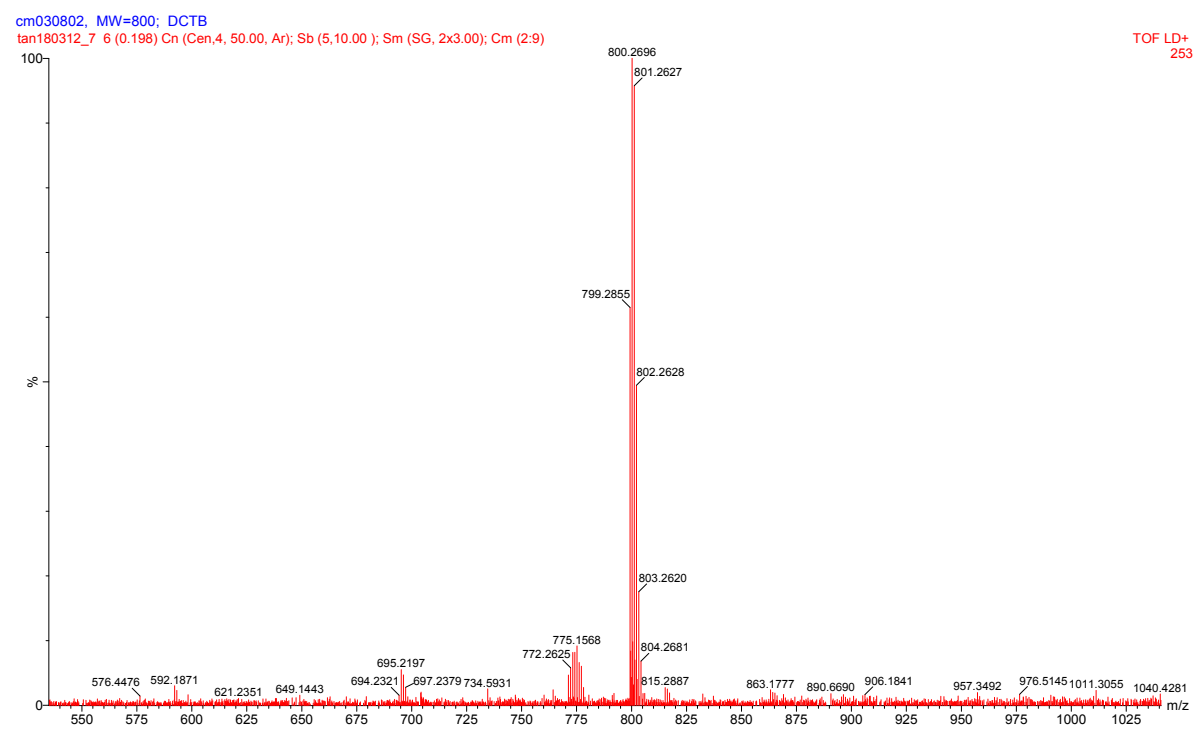

Figure S2. HRMS spectrum of TPP-4CHO. 
$+1\||\|\mid\|$
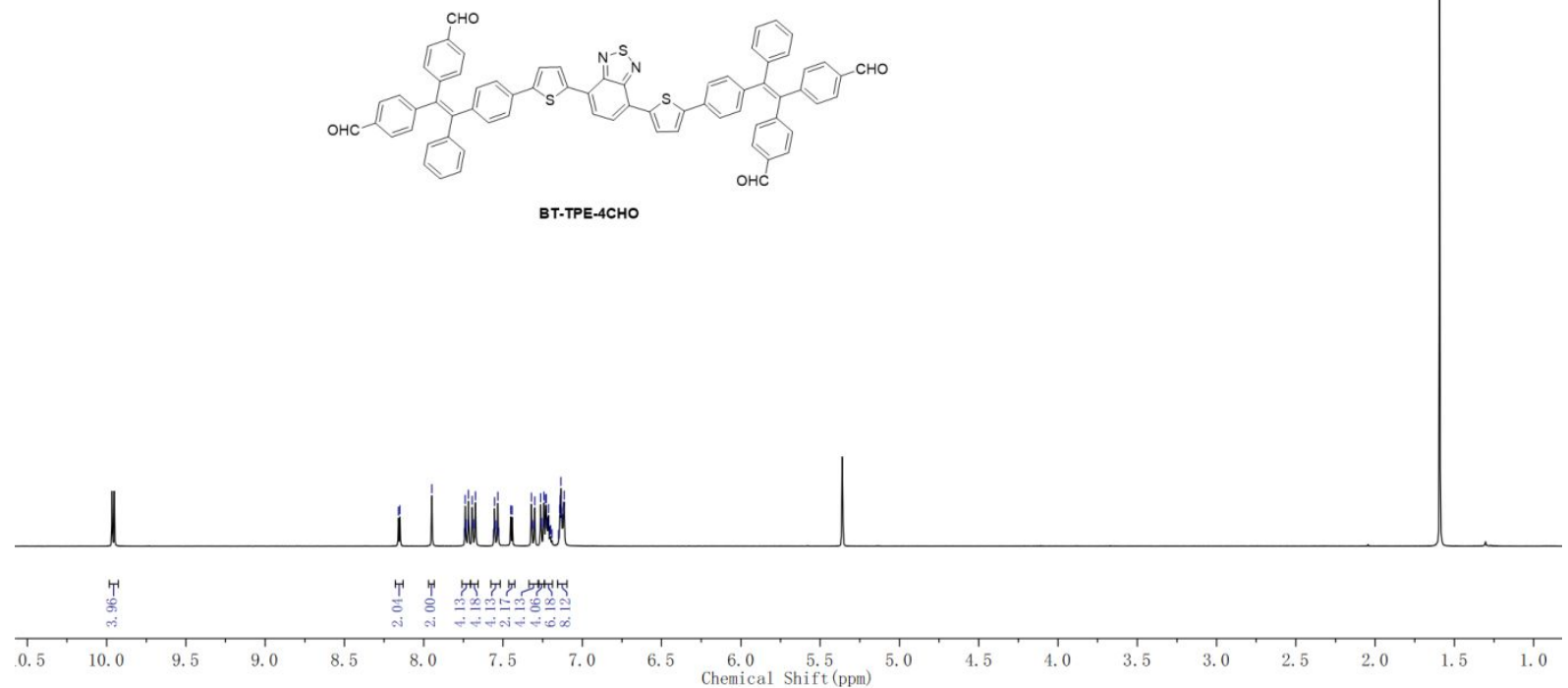

Figure S3. ${ }^{1} \mathrm{H}$ NMR spectrum of BT-TPE-4CHO in $\mathrm{CD}_{2} \mathrm{Cl}_{2}$. 


\section{MALDI,BT-3,201811022}

Analysis Info

Analysis Name

Method

Sample Name

Comment

Acquisition Parameter

D:IDatalMALDII201810822IBT-4CHO-3_0_L3_000001.d

MALDI_P_100-3000

MURU-N-ES

Acquisition Date $8 / 22 / 2018$ 5:40:42 PM

Operator

Instrument solariX

Polarity

Broad

Broadband High Mass

Source Accumulation

ion Accumulation Time $0.300 \mathrm{sec}$

Single MS

Positive
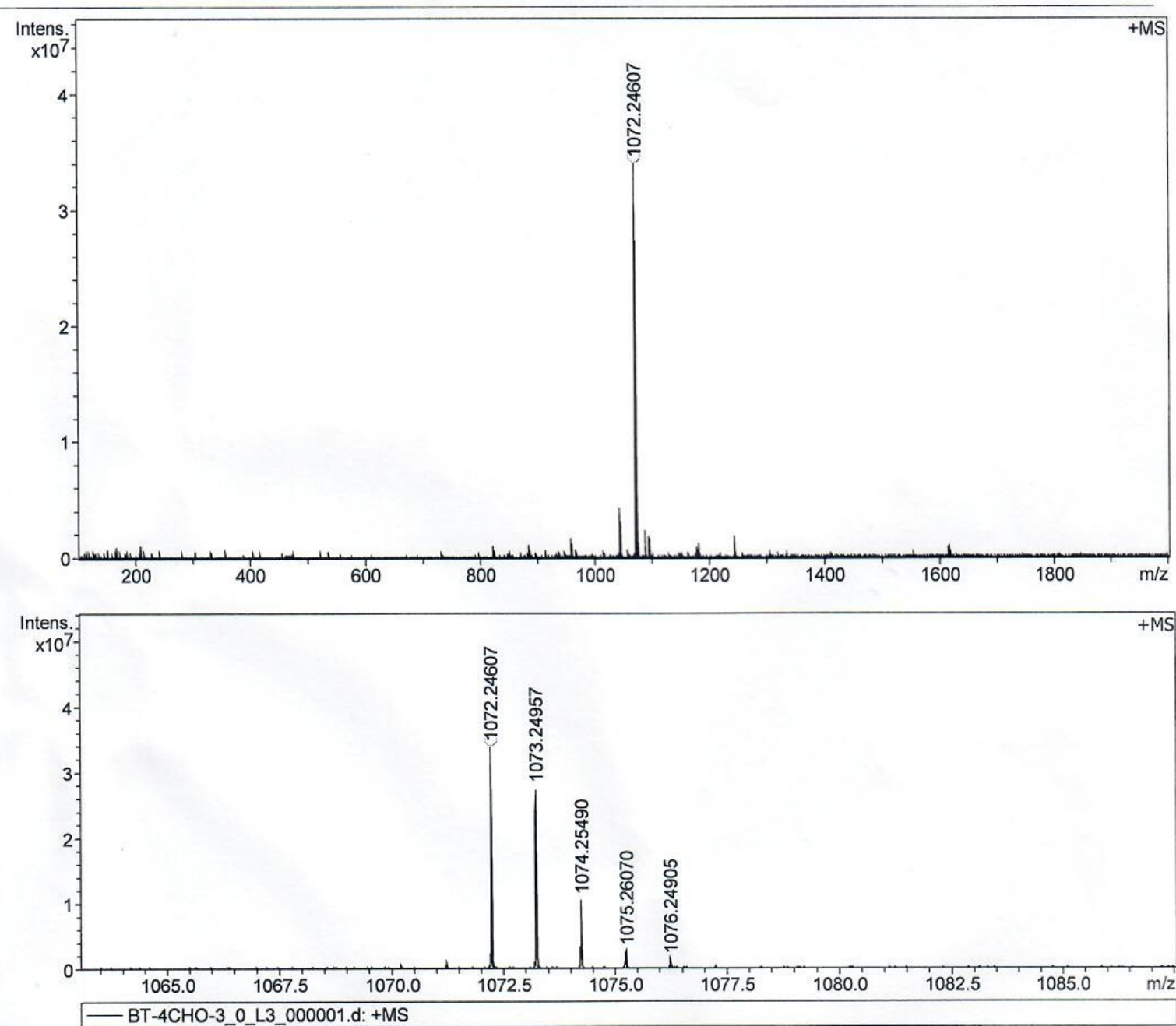

Meas. $\mathrm{m} / \mathrm{z}$ \# Ion Formula

Score

$\mathrm{m} / \mathrm{z}$

Acquired Scans

No. of Cell Fills

No. of Laser Shots

2

$\begin{array}{ll}\text { Laser Power } & 34.2 \mathrm{Ip} \\ \text { Laser Shot Frequency } & 0.020 \mathrm{se}\end{array}$

Data Acquisition Size

Wed Aug 22 05:38:05

Dize 4194304

Apodization

Sine-Bell Multiplication

072.246069 $1 \mathrm{C} 70 \mathrm{H} 44 \mathrm{~N} 2 \mathrm{O} 4 \mathrm{~S} 3$

$100.00 \quad 1072.245772$

err [ppm] Mean err [ppm] mSigma $\mathrm{rdb} \mathrm{e}^{-}$Conf N-Rule

$\begin{array}{lll}-1.1 & 91.4 & 50.0\end{array}$

Figure S4. HRMS spectrum of BT-TPE-4CHO. 

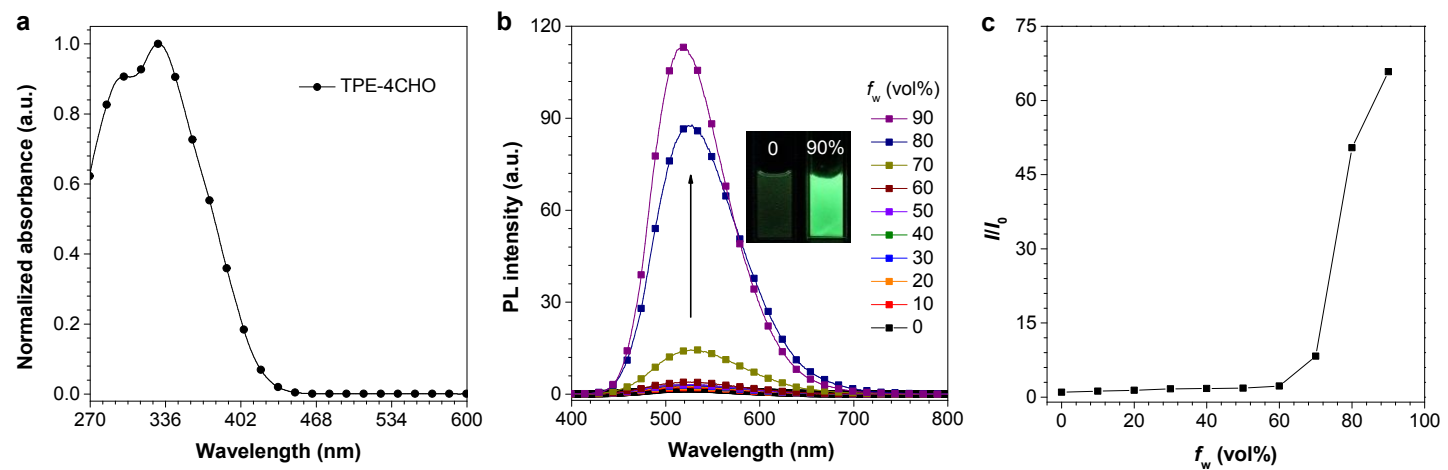

Figure S5. The photophysical properties of TPE-4CHO. (a) UV-vis spectrum of TPE$4 \mathrm{CHO}$ in THF solution $\left(1 \times 10^{-5} \mathrm{M}\right)$. (b) PL spectra of TPE-4CHO in THF solution and THF/Water mixtures with different water fractions $\left(f_{w}\right)$, insets show the fluorescence photos of TPE-4CHO in the solution with the $f_{w}$ of 0 and $90 \%$. (c) Plot of the fluorescence intensity against the $f_{w}$.
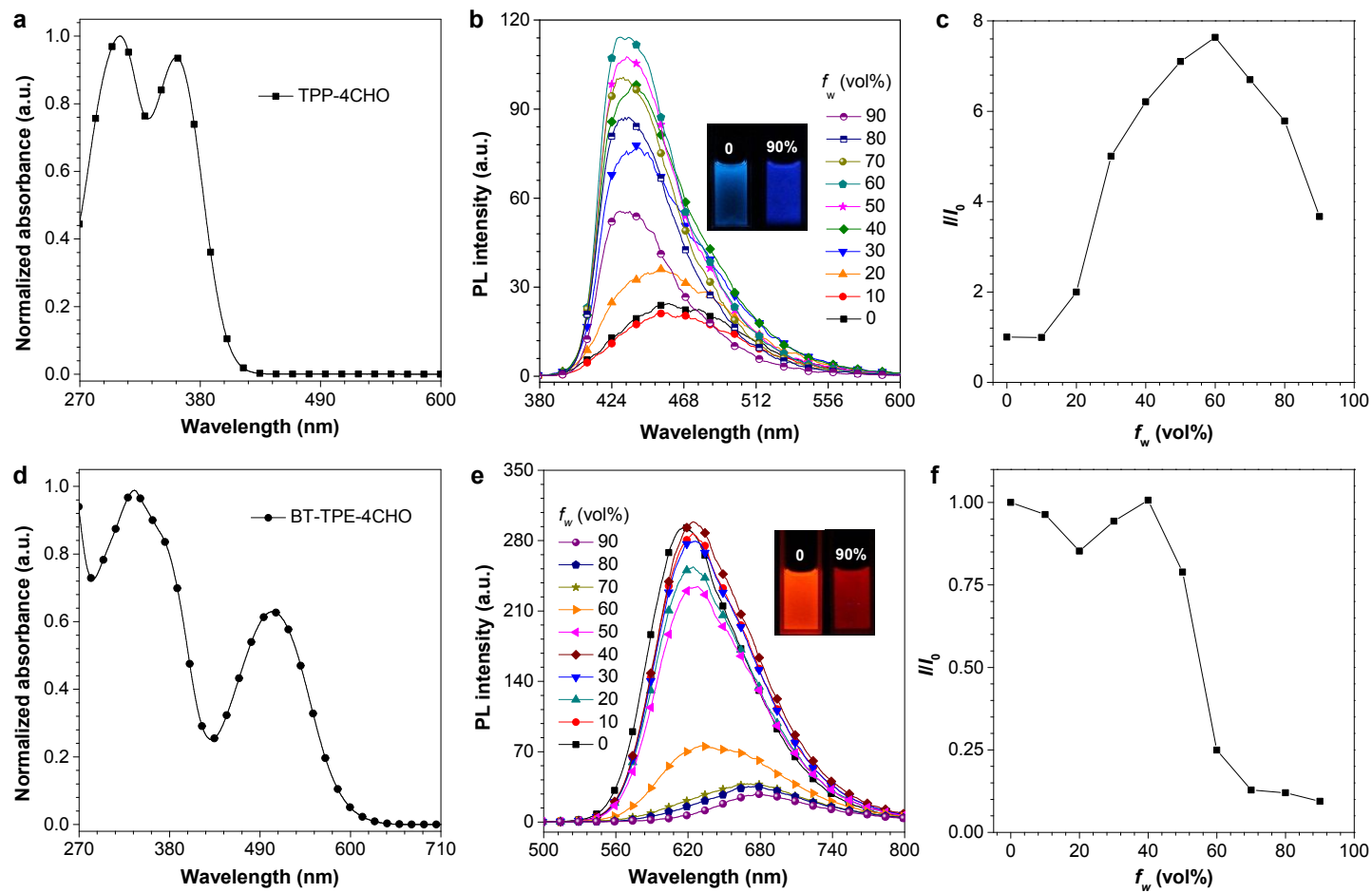

Figure S6. The photophysical properties of TPP-4CHO BT-TPE-4CHO. (a) and (d) UVvis spectrum of TPP-4CHO and BT-TPE-4CHO in THF solution $\left(1 \times 10^{-5} \mathrm{M}\right)$. (b) and (e) PL spectra of TPP-4CHO and BT-TPE-4CHO in THF solution and THF/Water mixtures with different water fractions $\left(f_{w}\right)$, insets show the fluorescence photos of TPP-4CHO and BT-TPE- 
$4 \mathrm{CHO}$ in the solution with the $f_{w}$ of 0 and $90 \%$. (c) and (f) Plots of the fluorescence intensity against the $f_{w}$ for TPP-4CHO and BT-TPE-4CHO.

\section{Characterizations of gelation process}

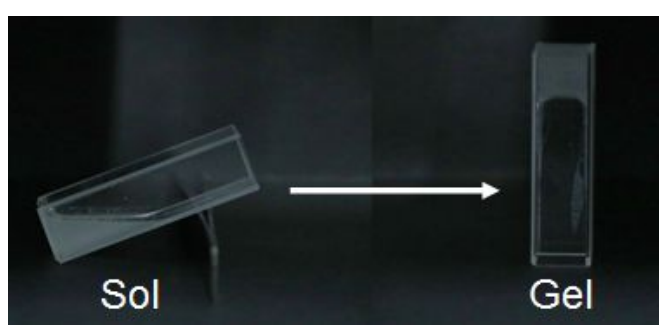

Figure S7. Digital images mixture from sol to gel with BTA $(0.1 \mathrm{mmol}), \mathrm{NH}_{2}-\mathrm{PDMS}^{-\mathrm{NH}_{2}}$ $\left(\mathrm{M}_{\mathrm{n}}: 5000-7000,0.8 \mathrm{~g}\right)$ and TPE-4CHO $\left(1 \times 10^{-5} \mathrm{mmol}\right)$.
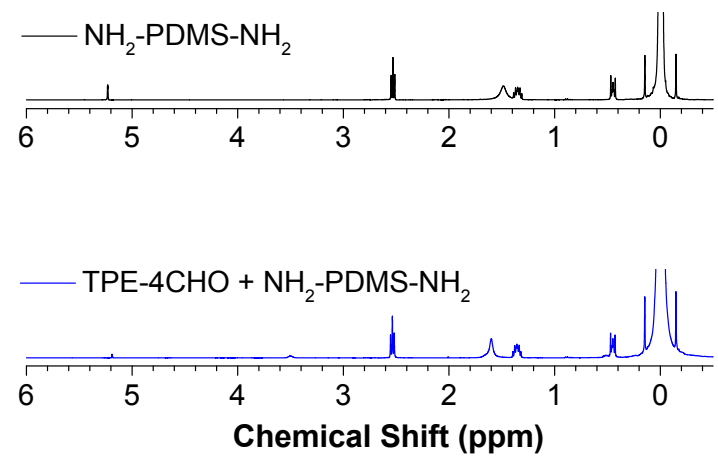

Figure S8. ${ }^{1} \mathrm{H}$ NMR of $\mathrm{NH}_{2}-\mathrm{PDMS}-\mathrm{NH}_{2}$ without and with TPE-4CHO in $\mathrm{CDCl}_{2}$ from 6.0 to $-0.5 \mathrm{ppm}$.

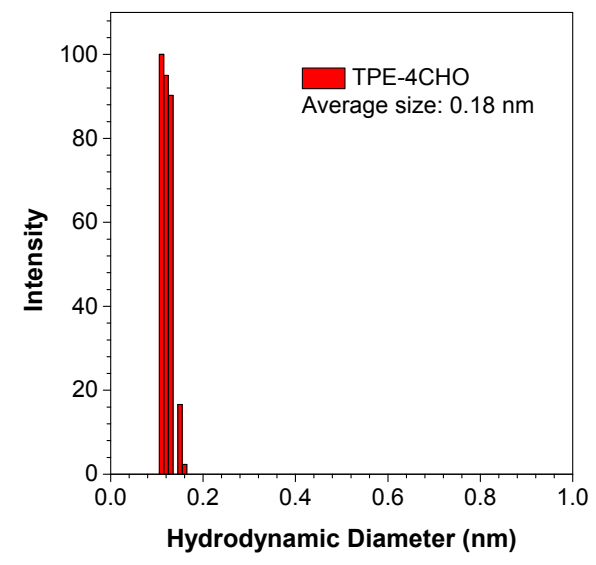

Figure S9. DLS analysis of aggregation of TPE-4CHO in DMF solution. 

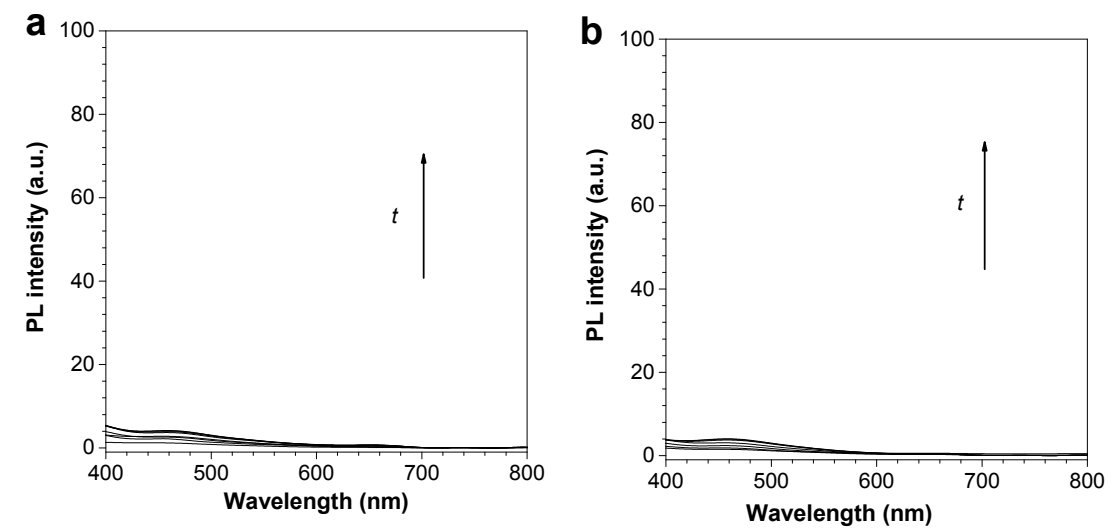

Figure S10. The PL spectra of gelation process. PL spectra of gelation process for the mixture of BTA (0.1 mmol), $\mathrm{NH}_{2}-\mathrm{PDMS}-\mathrm{NH}_{2}\left(\mathrm{M}_{\mathrm{n}}: 5000-7000,0.8 \mathrm{~g}\right)$ (a) without AIE-active TPE-4CHO and (b) with aldehyde-free AIE-active TPE-4OCH $\left(1 \times 10^{-5} \mathrm{mmol}\right)$ at different reaction time.
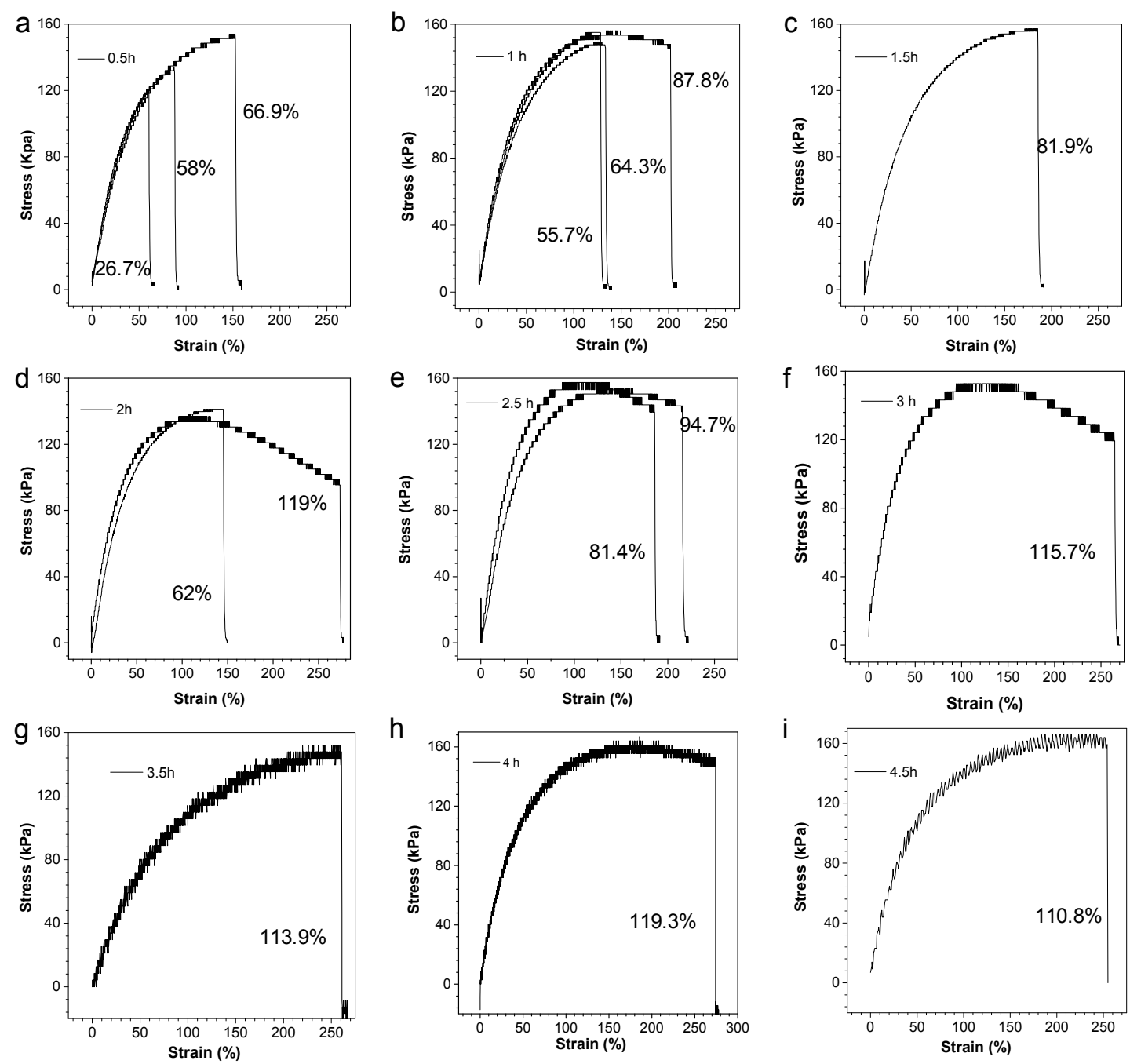
Figure S11. The uniaxial tensile stress-strain profiles of healable TPE-4CHO-containing PDMS self-healing gels after healing for (a) 0.5, (b) 1, (c) 1.5, (d) 2, (e) 2.5, (f) 3, (g) 3.5, (h) 4 and (i) $4.5 \mathrm{~h}$, with the healing efficiencies labeled.

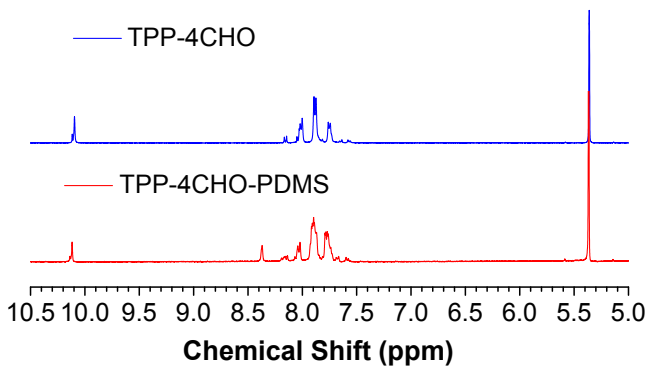

b

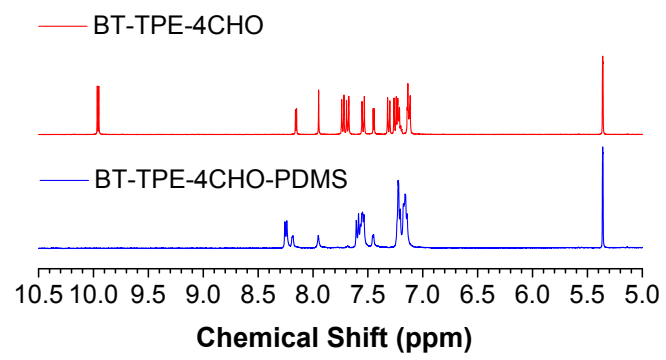

Figure S12. ${ }^{1} \mathrm{H}$ NMR of (a) TPP-4CHO and (b) BT-TPE-4CHO without and with $\mathrm{NH}_{2}$ PDMS- $\mathrm{NH}_{2}$ in $\mathrm{CDCl}_{2}$ from 10.5 to $5.0 \mathrm{ppm}$.

\section{Tunable emissive self-healing PDMS belts}

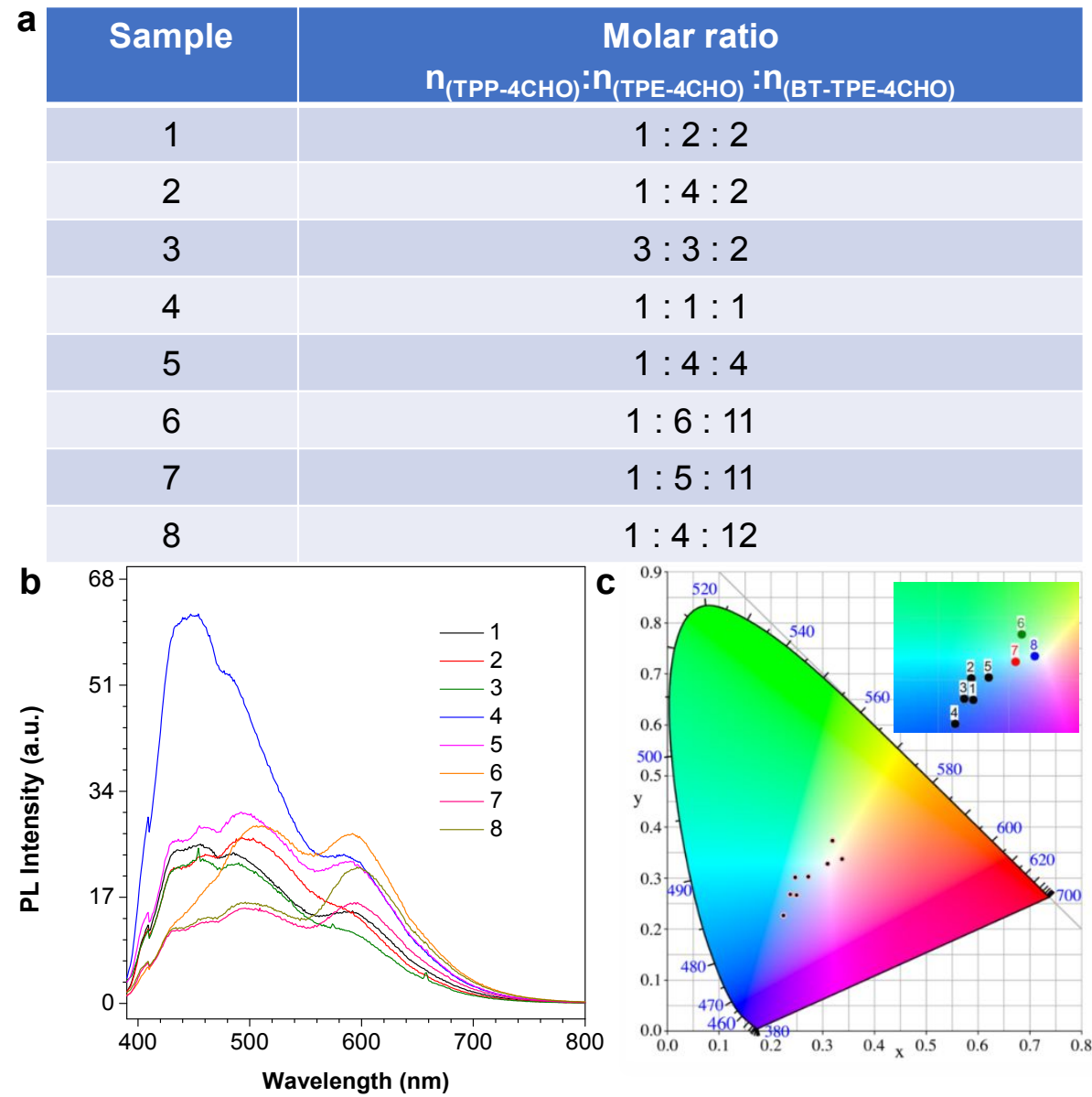


Figure S13. (a) The self-healing PDMS gels with different molar ratios of TPP-4CHO, TPE4CHO, and BT-TPE-4CHO, and their PL spectra (b) with the corresponding CIE 1931 coordinates (c).

4. Uniaxial tensile stress-strain profiles.

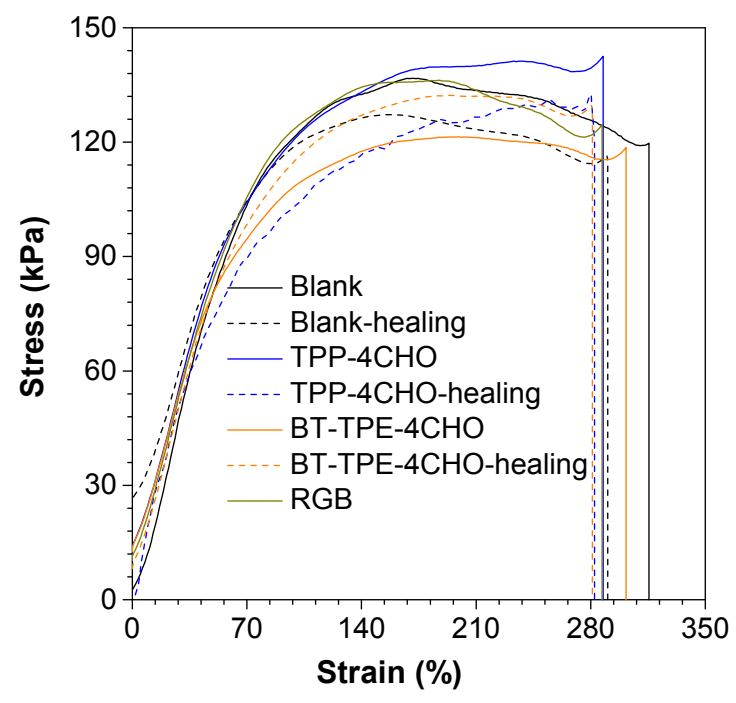

Figure S14. The uniaxial tensile stress--strain profiles of original and healed AIEgencontaining PDMS films.

5. The re-usability for the fluorescent self-healing codes.

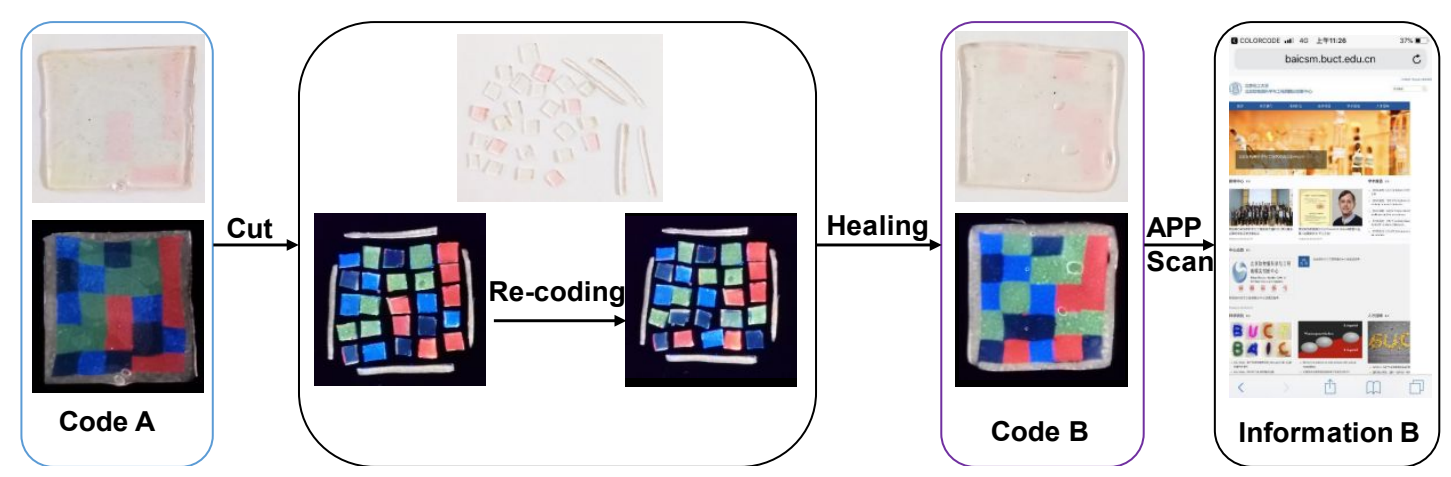

Figure S15. The re-usability for the fluorescent self-healing codes.

\section{References}

(1) Luo, W.; Zhu, Y.; Zhang, J.; He, J.; Chi, Z.; Miller, P. W.; Chen, L.; Su, C. Y. A dynamic covalent imine gel as a luminescent sensor. Chem. Commun. 2014, 50, 11942-11945. 
(2) Chen, M.; Nie, H.; Song, B.; Li, L.; Sun, J. Z.; Qin, A.; Tang, B. Z. Triphenylaminefunctionalized tetraphenylpyrazine: facile preparation and multifaceted functionalities. $J$. Mater. Chem. C, 2016, 4, 2901-2908. 